\title{
Comparative analysis of secreted protein evolution using expressed sequence tags from four poplar leaf rusts (Melampsora spp.)
}

\author{
David L Joly ${ }^{1}$, Nicolas Feau ${ }^{1,3}$, Philippe Tanguay ${ }^{1}$, Richard C Hamelin ${ }^{1,2^{*}}$
}

\begin{abstract}
Background: Obligate biotrophs such as rust fungi are believed to establish long-term relationships by modulating plant defenses through a plethora of effector proteins, whose most recognizable feature is the presence of a signal peptide for secretion. Since the phenotypes of these effectors extend to host cells, their genes are expected to be under accelerated evolution stimulated by host-pathogen coevolutionary arms races. Recently, whole genome sequence data has allowed the prediction of secretomes, facilitating the identification of putative effectors.

Results: We generated cDNA libraries from four poplar leaf rust pathogens (Melampsora spp.) and used computational approaches to identify and annotate putative secreted proteins with the aim of uncovering new knowledge about the nature and evolution of the rust secretome. While more than half of the predicted secretome members encoded lineage-specific proteins, similarities with experimentally characterized fungal effectors were also identified. A SAGE analysis indicated a strong stage-specific regulation of transcripts encoding secreted proteins. The average sequence identity of putative secreted proteins to their closest orthologs in the wheat stem rust Puccinia graminis f. sp. tritici was dramatically reduced compared with non-secreted ones. A comparative genomics approach based on homologous gene groups unravelled positive selection in putative members of the secretome.

Conclusion: We uncovered robust evidence that different evolutionary constraints are acting on the rust secretome when compared to the rest of the genome. These results are consistent with the view that these genes are more likely to exhibit an effector activity and be involved in coevolutionary arms races with host factors.
\end{abstract}

\section{Background}

Rust fungi or Pucciniales (= Uredinales) represent the largest group of fungal plant pathogens, including more than 7000 species that possess the most complex life cycles in the Kingdom Fungi [1]. Some of these obligate biotrophs have been of long standing concern for agriculture and forestry while others have emerged in recent epidemics. For instance, poplar leaf rusts belonging to the genus Melampsora are considered as the world's most important disease of poplars [2]. Selection for durable resistance to these pathogens is thus an important challenge for poplar breeders [3]. Although poplar breeding programs have been in place for decades in

\footnotetext{
* Correspondence: richard.hamelin@ubc.ca

'Natural Resources Canada, Canadian Forest Service, Laurentian Forestry Centre, 1055 du PEPS, P.O. Box 10380, Stn. Sainte-Foy, Québec, QC, GIV 4C7,
} Canada

( 2010 Joly et al; licensee BioMed Central Ltd. This is an Open Access article distributed under the terms of the Creative Commons Attribution License (http://creativecommons.org/licenses/by/2.0), which permits unrestricted use, distribution, and reproduction in any medium, provided the original work is properly cited.
Europe, clones selected for complete resistance against rust have increasingly succumbed in time to new races of Melampsora larici-populina [4]. Sustainability of newly selected resistance clearly requires a better understanding of the molecular mechanisms involved in PopulusMelampsora interactions.

Prokaryotic and eukaryotic plant pathogens have evolved highly advanced strategies to engage their hosts in intimate contacts and deliver suites of effector proteins to modulate plants' innate immunity and enable parasitic colonization [5-12]. Understanding the translocation mechanisms of bacterial pathogen effectors inside host cells has been an outstanding breakthrough with the characterization of the type III secretion system. This export apparatus enables a bacterium to manipulate host cellular processes by injecting effector proteins into the host cytoplasm [7]. Similarly, plant-parasitic 
nematodes have developed diverse relationships to obtain nutrients from their host plants. Perhaps their most evolutionary sophisticated adaptations are effector proteins encoded by parasitism genes expressed in oesophageal gland cells and secreted through a protrusible feeding spear, called a stylet $[5,6]$. However, still little is known about such translocation machineries in filamentous pathogens (mainly fungi and oomycetes), although another specialized biotrophic infection cell called the haustorium is thought to be involved [13-15]. The haustorium invaginates host cells and makes near-direct contact with the host plasma membrane, where it plays a crucial role in nutrient acquisition. This structure is a regulatory hub involved in the manipulation of host metabolism and the suppression of host defenses, which allows the establishment of a successful biotrophic relationship [16-19]. The concomitance of haustoria formation with the induction of a programmed cell death response termed the hypersensitive response (HR) suggests a significant role for this structure in delivering effector proteins into the infected host cell $[14,20]$.

Key insights have emerged from the recent identification of filamentous pathogen effectors with avirulence activity inducing plant defense responses and HR [21-26]. Most of the avirulence genes identified encode small proteins with $\mathrm{N}$-terminal signal peptides that direct them through the endoplasmic reticulum secretory pathway $[14,27]$. While effector genes reside in pathogen genomes, their products essentially generate phenotypes that extend to host cells and tissues, and are hence likely to be the direct target of the never-ending coevolutionary conflict between host and pathogen $[28,29,36]$. In fact, avirulence proteins recognition by plant resistance proteins imposes selection against effector function, and pathogen effector proteins probably overcome resistance through diversification of the genes encoding them [30]. For instance, several avirulence genes or their plant counterparts display molecular hallmarks of positive selection [21,22,25,30-38]. Recently, the availability of filamentous plant pathogen genome sequences facilitated the cataloguing of whole secretomes using computational analyses, thus allowing the identification of putative effectors [39-43]. Indeed, Tyler et al. [41] provided evidence that secreted proteins have been subject to accelerated evolution by contrasting the genome sequences of Phytophthora ramorum and Phytophthora sojae.

Here we provide an overview of the expressed secretome of poplar leaf rusts belonging to the genus $\mathrm{Mel}$ ampsora. We constructed cDNA libraries for four related poplar leaf rust pathogens with different host specificities to test for the signature of selection in these rust secretomes and used computational tools to annotate putative secreted proteins. A comparative genomics approach based on homologous gene groups (HGGs) was undertaken to evaluate the extent to which secretome members are under different evolutionary constraints. We describe adaptive evolution (positive selection) in genes encoding secreted proteins of poplar leaf rusts, in agreement with the idea that these genes are expected to display an effector activity and be involved in the escalating and reciprocal coevolutionary arms race with host resistance factors.

\section{Results and Discussion}

\section{Defining the poplar leaf rust secretome}

We constructed cDNA libraries from ex planta material of four different Melampsora taxa with different host specificities: the Eurasian M. larici-populina, the North American M. occidentalis, and two formae speciales of the North American M. medusae, M. medusae f. sp. deltoidae and M. medusae f. sp. tremuloidae (Table 1; see Methods). This allowed the comparison of expressed sequence tags (ESTs) with their putative orthologues and made it possible to incorporate evolutionary information into our analyses. In order to extend our dataset with candidate effectors expressed in and secreted from haustoria, we generated an additional haustoriumenriched library (biotrophic stage) of M. larici-populina. In total, 14,904 clones were sequenced in this study, which represented 6,044 unique sequences (unisequences, i.e. all contigs and singletons). Clone sequences are available under GenBank accession numbers GW672673 to GW687576. The identification of transcripts coding for secreted proteins was carried out using an in silico analysis including a series of prediction

Table 1 Summary of Melampsora cDNA libraries characteristics

\begin{tabular}{|c|c|c|c|c|c|c|}
\hline Species/Natural host & Material & Unisequences & Contigs & Singletons & Putative $S^{a}(\%)$ & Putative $\mathbf{S}+{ }^{\mathbf{b}}(\%)$ \\
\hline M. larici-populina/Populus nigra & Haustoria & 1148 & 427 & 721 & $54(4.7)$ & $72(6.3)$ \\
\hline M. larici-populina/P. nigra & Ex planta & 787 & 266 & 521 & $51(6.5)$ & $92(11.7)$ \\
\hline M. medusae f. sp. deltoidae/P. deltoides & Ex planta & 937 & 452 & 485 & $95(10.1)$ & $131(14.0)$ \\
\hline M. medusae f. sp. tremuloidae/P. tremuloides & Ex planta & 1547 & 571 & 976 & $98(6.3)$ & $246(15.9)$ \\
\hline M. occidentalis/P. trichocarpa & Ex planta & 1625 & 493 & 1132 & $107(6.6)$ & $148(9.1)$ \\
\hline
\end{tabular}

${ }^{\mathrm{a}} \mathrm{S}$ : Initial predicted set of unisequences encoding putative secreted proteins.

${ }^{\mathrm{b}} \mathrm{S}+$ : Final set of unisequences encoding putative secreted proteins, following reassignments based on reciprocal BLAST. 
algorithms (SignalP, TargetP and TMHMM), yielding 405 sequences encoding putative proteins with predicted secretory signal peptides (\# Putative $S$, Table 1). A number of sources exist that lead to false prediction, i.e. selecting individual proteins that should not be included in the secretome. For example, mitochondrial localization sequences and $\mathrm{N}$-terminal transmembrane anchors are frequently interpreted as signal peptides [44]. Even though no computational method seems fully accurate, the prediction algorithms included in our approach should have excluded such false positives. The assignment of a protein to the secretome is also totally dependent on having the full-length open reading frame (ORF). An inaccurate $a b$ initio gene prediction or an incomplete ORF could lack an additional sequence encoding a transmembrane domain or a signal peptide. For this reason, we conducted reciprocal blast between libraries to reduce the number of false assignments due to partial or mispredicted ORFs. Most reassignments were false negatives with truncated $\mathrm{N}$ termini, thus increasing the number of putative secreted members to 689 (\# Putative S+, Table 1).

\section{Functional annotation of the poplar leaf rust secretome: novel proteins and the identification of orthologues}

This S+ dataset was used as search query in BLASTX on the non-redundant UniProtKB database to find sequences with significant matches. Furthermore, to develop an understanding of how protein secretion by poplar leaf rusts might be related to specialized functions or processes, we used the PFAM [45] and Gene Ontology (GO) [46] databases to determine whether any class of proteins was more likely to be found in the $\mathrm{Mel}$ ampsora secreted proteins. In addition, we used the Gene Ontology methodology within a statistical framework to determine whether any GO terms were significantly enriched in $\mathrm{S}+$ proteins when compared to non-secreted proteins (NS). For 248 candidates, i.e. 36\% of the S+ dataset, significant similarity was found in the UniProtKB database, mostly among putative effectors or proteolytic and carbohydrate-degrading enzymes from other fungal species (Table 2). Less than a quarter of the unisequences had similarity to one or more PFAM domain predictions or GO term assignments. The most abundantly represented PFAM domains in the poplar leaf rusts secretome are presented in Additional File 1, and GO classifications are depicted in Figure 1.

Host infection by biotrophic fungi is believed to involve the secretion of effectors that suppress plant defenses and alter cellular metabolism to fulfill the requirements of the invading pathogen [47]. Among the candidates that had significant similarity to known sequences, homologies with potential effectors previously identified in the haustoria of other rust species were observed. Interestingly, 22 candidates had similarities with eight "haustorially expressed secreted proteins" (HESPs) from Melampsora lini identified using a similar bioinformatics approach. Some of these HESPs were shown to co-segregate with known avirulence genes and are proven HR elicitors in flax, such as the avirulence protein AvrM [26]. The percentage of identity between flax rust and poplar leaf rust HESPs differed greatly. For instance, HESP-379 had close homologues in Melampsora spp. (identity: 93\%), while AvrM appeared less conserved (identity: 26\%). Other candidates had similarities with Rust Transferred Protein (RTP1) from Uromyces fabae, a small secreted protein that is specifically expressed in broad bean rust haustoria and translocated into host cells. This protein accumulates within the cytoplasm of the infected host cell and in the host nucleus, suggesting a role in influencing host gene expression [13]. Homologies with other proteins thought to contribute to pathogenesis were unravelled, with 19 unisequences having similarity to CFEM domain

Table 2 Similarity of Melampsora unisequences to sequences from UniProtKB, BasidiomycotaDB and PuccinialesDB

\begin{tabular}{|c|c|c|c|c|c|c|}
\hline \multirow[t]{2}{*}{ Library } & \multicolumn{2}{|c|}{$\begin{array}{l}\text { \% with homologues } \\
\text { in } \\
\text { UniProtKB }\end{array}$} & \multicolumn{2}{|c|}{$\begin{array}{l}\text { \% with homologues in } \\
\text { BasidiomycotaDB }\end{array}$} & \multicolumn{2}{|c|}{$\begin{array}{c}\text { \% with homologues in } \\
\text { PuccinialesDB }\end{array}$} \\
\hline & $\mathrm{NS}^{\mathrm{a}}$ & $\mathrm{S}+{ }^{\mathrm{b}}$ & NS & S+ & NS & S+ \\
\hline M. larici-populina haustoria & 22.6 & 13.9 & 21.5 & 13.9 & 29.6 & 23.6 \\
\hline M. larici-populina ex planta material & 54.0 & 54.3 & 54.1 & 50.0 & 62.4 & 56.5 \\
\hline M. medusae f. sp. deltoidae ex planta material & 56.2 & 50.4 & 54.7 & 45.8 & 64.9 & 56.5 \\
\hline M. medusae f. sp. tremuloidae ex planta material & 36.7 & 23.6 & 38.3 & 23.2 & 47.4 & 35.4 \\
\hline M. occidentalis ex planta material & 47.4 & 43.9 & 49.3 & 37.2 & 59.6 & 54.7 \\
\hline
\end{tabular}

BasidiomycotaDB included Basidiomycota (excluding Pucciniales) EST sequence 6-frame translations and protein sequences from the non-redundant database of $\mathrm{NCBI}$ and gene models from Coprinus cinereus Okayama 7 (\#130), Cryptococcus neoformans var. grubii serotype A, strain H99, Laccaria bicolor S238N-H82, Malassezia globosa CBS 7966, Phanerochaete chrysosporium RP78, Postia placenta MAD-698, Sporobolomyces roseus IAM 13481 and Ustilago maydis 521.

PuccinialesDB included Pucciniales EST sequence 6-frame translations and protein sequences from the non-redundant database of NCBI and gene models from $P$. graminis $\mathrm{f}$. sp. tritici CRL 75-36-700-3. BLASTX hits were considered significant when E-value $\leq 1 \mathrm{e}-4$.

${ }^{a} \mathrm{NS}$ : Final set of unisequences not predicted to encode putative secreted proteins.

${ }^{b} \mathrm{~S}+$ : Final set of unisequences encoding putative secreted proteins, following reassignments based on reciprocal BLAST. 
proteins $(\mathrm{CFEM}=$ Common in Fungal Extracellular and Membrane). This particular domain is an eight cysteinecontaining domain for which members are proposed to have important roles in fungal pathogenesis [48], and it was by far the most highly represented PFAM domain in the $\mathrm{S}+$ dataset. CFEM-containing proteins could function as cell-surface receptors, signal transducers, or adhesion molecules in host-pathogen interactions [48]. Moreover, five unisequences had significant similarity to gEgh16/gEgh16 $H$ proteins from Blumeria graminis, a large family potentially involved in host-pathogen interactions [49]. An appressorium-specific expression pattern was described for numerous $g E g h 16 / g E g h 16 H$ homologues, including virulence genes GAS1 (MAS3) and GAS2 (MAS1) from Magnaporthe grisea. GAS1 or GAS2 deletion mutants had no defect in vegetative growth, conidiation or appressoria formation, but were reduced in appressorial penetration and lesion development [50].

The diverse ecological niches of fungal species are mirrored in their secretome, which includes gene families encoding various proteolytic and carbohydrate- degrading enzymes known to act on the linkages found in plant cell walls and compatible with the array of nutritional sources they can exploit [47]. Consistent with the molecular function GO analysis (Figure 1), $36.56 \%$ and $47.88 \%$ of Melampsora secreted proteins with a GO assignment were involved in binding (GO:0005488) and catalytic activity (GO:0003824), respectively. Note that there was a trend towards concentration of a distinct set of processes and functions in the group of proteins making up the Melampsora secretome. Significantly higher proportions of secreted proteins, relative to the entire dataset, were assigned to the following functions: carbohydrate and ion binding, and hydrolase and oxidoreductase activity (GO:0030246 and GO:0043167, and GO:0016787 and GO: 0016491). There also appeared to be enrichment of proteins involved in processes related to cell adhesion (GO:0007155), response to stimulus (GO:0050896), regulation of molecular function (GO:0065009), carbohydrate and lipid transport (GO:0008643 and GO:0006869), and primary metabolic process (GO:0044238), including oxygen and reactive oxygen

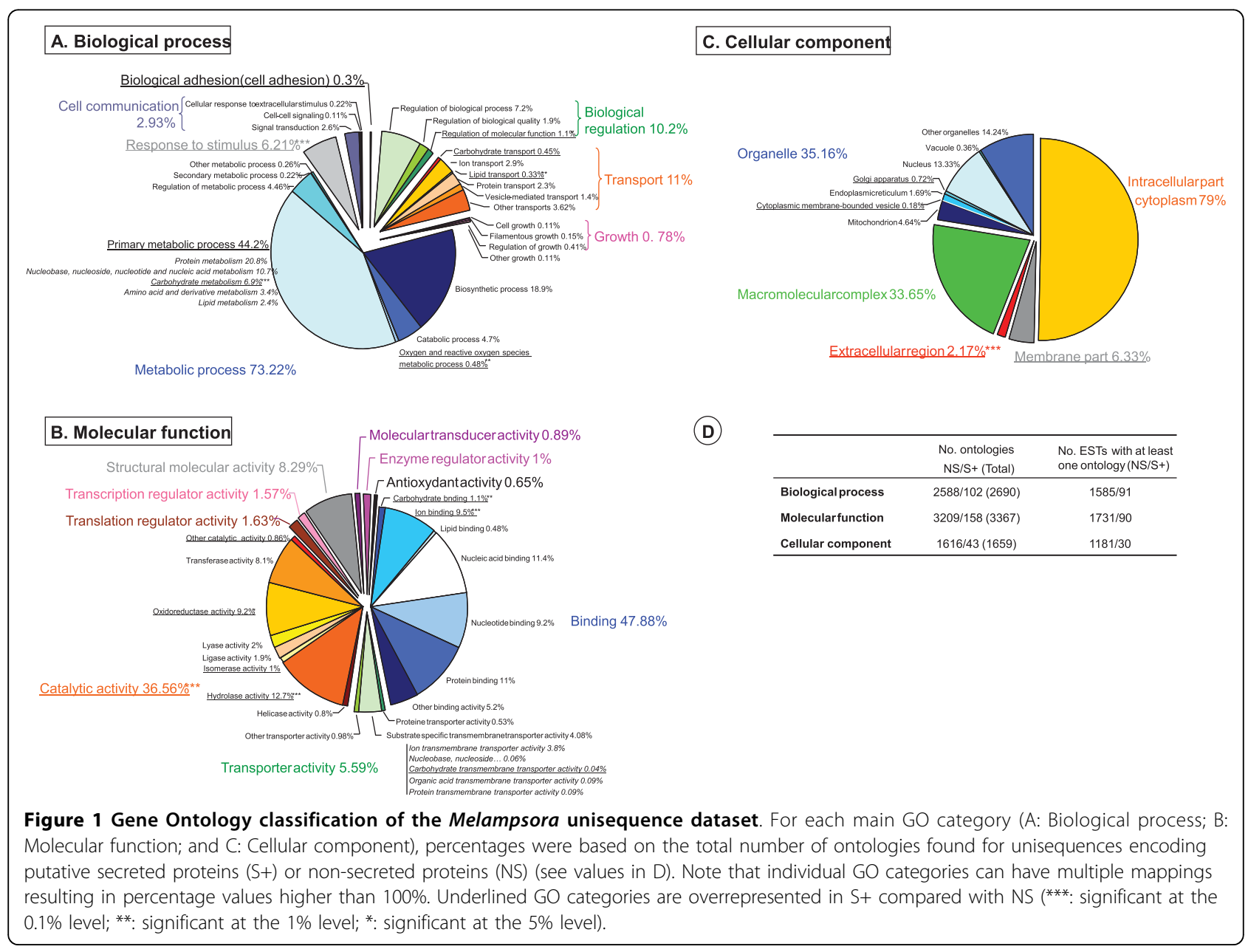


species metabolic process (GO:0006800) and carbohydrate metabolic process (GO:0005975). Apart from putative effectors, members of the secretome had homology to a battery of glycoside hydrolases and subtilisin-like serine proteases that likely contribute to the penetration of the plant cuticle and cell wall [47]. In fact, glycosyl hydrolase 16 (PF00722) was the second most represented PFAM domain in the secretome, followed by domains typically found in proteolytic enzymes (Peptidase_S8 [PF00082], Subtilisin_N [PF05922] and Asp [PF00026]) (Additional File 1). A class of secreted proteins exhibiting the ability to neutralize reactive oxygen species (ROS), and including $\mathrm{Mn}$ and $\mathrm{Cu} / \mathrm{Zn}$ superoxide dismutases, was also uncovered by this survey. This finding was not surprising as it is known that rust fungi prevent a variety of non-specific defense responses in invaded cells, thus allowing the establishment of the long-term biotrophic relationship between rust fungi and living host cells [51]. Such host responses frequently involve the production of ROS, whose detoxification is essential for the establishment of the pathogen. A Mn superoxide dismutase homologue had previously been reported in the haustorial stage of Puccinia triticina [52] and was differentially-expressed in Uromyces appendiculatus germlings during early appressorium development [53]. Concordant with these observations, previous studies have demonstrated the upregulation of several host genes encoding enzymes of the redox regulation pathways during Populus-Melampsora interactions [54,55]. Another group of interesting secreted proteins identified here that may be critical for evading host recognition or protecting fungal cell wall from hydrolysis by host enzymes were chitin deacetylases, which have already been described in libraries from Phakopsora pachyrhizi [56] and P. triticina [52]. The conversion of chitin into chitosan by de- $N$-acetylation not only protects fungal infection structures from hydrolytic attack by chitinases present in the host tissue, it also prevents the release of chitin oligomers responsible for the triggering of resistance reactions [57].

This functional annotation established the secretome's ability to perform diverse roles in pathogenicity and interactions with host cells. However, for the major part of the secretome, no GO or PFAM domains could be assigned. For 441 candidates, i.e. $64 \%$ of the S+ dataset, no significant similarity was found to known proteins in the UniProtKB database (E-value > 1e-4) (Table 2). To ascertain that the large number of unmatched proteins identified in this study was not due to the paucity of Pucciniales (or even Basidiomycota) sequences in international databases [52], we constructed two specific databases (BasidiomycotaDB and PuccinialesDB). BLASTX searches of the complete dataset of Melampsora unisequences $(\mathrm{S}+$ and NS) were performed against these databases. The percentage of unisequences with homologues was similar between BasidiomycotaDB and UniProtKB, indicating that the latter is not deficient in Basidiomycota sequences (Table 2). As previously observed with BLASTX searches, the percentage of S+ unisequences with homologues in both BasidiomycotaDB and PuccinialesDB was generally lower compared to NS. These results are consistent with the view that secreted effector proteins that subvert host-cell structure and functions often show very limited phylogenetic distribution and no obvious conserved motifs, being less evolutionarily conserved. Furthermore, the percentage of homologues for the haustorium-enriched library was surprisingly low considering that the whole gene set of another rust, Puccinia graminis f. sp. tritici, was included in the database. However, these results were comparable to observations made on the haustorial secretome of other rust fungi $[26,58]$. Most of the proteins secreted from the haustorium could be under rapid evolution and strong diversification due to host selective pressures and, therefore, be species-specific. Taken together, these results strongly indicate that a large portion of the secretome (and especially the haustorial secretome) of Melampsora may have virulence functions or be involved in host-pathogen interactions.

\section{Expression profiles of the poplar leaf rust secretome: stage-specificity}

Most abundantly represented members of the secretome had no evident homologues in the UniProtKB database (Additional File 2), or even in PuccinialesDB. However, some highly expressed candidates showed similarities to sequences suspected to be involved in pathogenicity or host-pathogen interactions (HESPs and CFEM-containing proteins). To obtain an accurate overview regarding the expression profiles of the secretome, we associated $S$ + members to 15 -bp tags from a serial analysis of gene expression (SAGE). We analyzed expression patterns at three time points during the infection process of $M$. larici-populina: twice during the pre-biotrophic stage (2 and 22 hours after inoculation), and once during the biotrophic stage (5 days after inoculation) (Feau et al., unpublished). The last two time points were also investigated on both susceptible and resistant hosts, i.e. during compatible and incompatible interactions. A quarter (182 unisequences) of the S+ members was confidently associated to a SAGE tag. An average linkage hierarchical clustering of SAGE patterns revealed strong stage specificities of the secretome (Figure 2), similar to observations made on $U$. fabae genes initially identified using the yeast signal sequence trap [58]. Genes expressed during pre-biotrophic growth were clearly turned off at later biotrophic stages, while others were induced only during the biotrophic stage. Global 


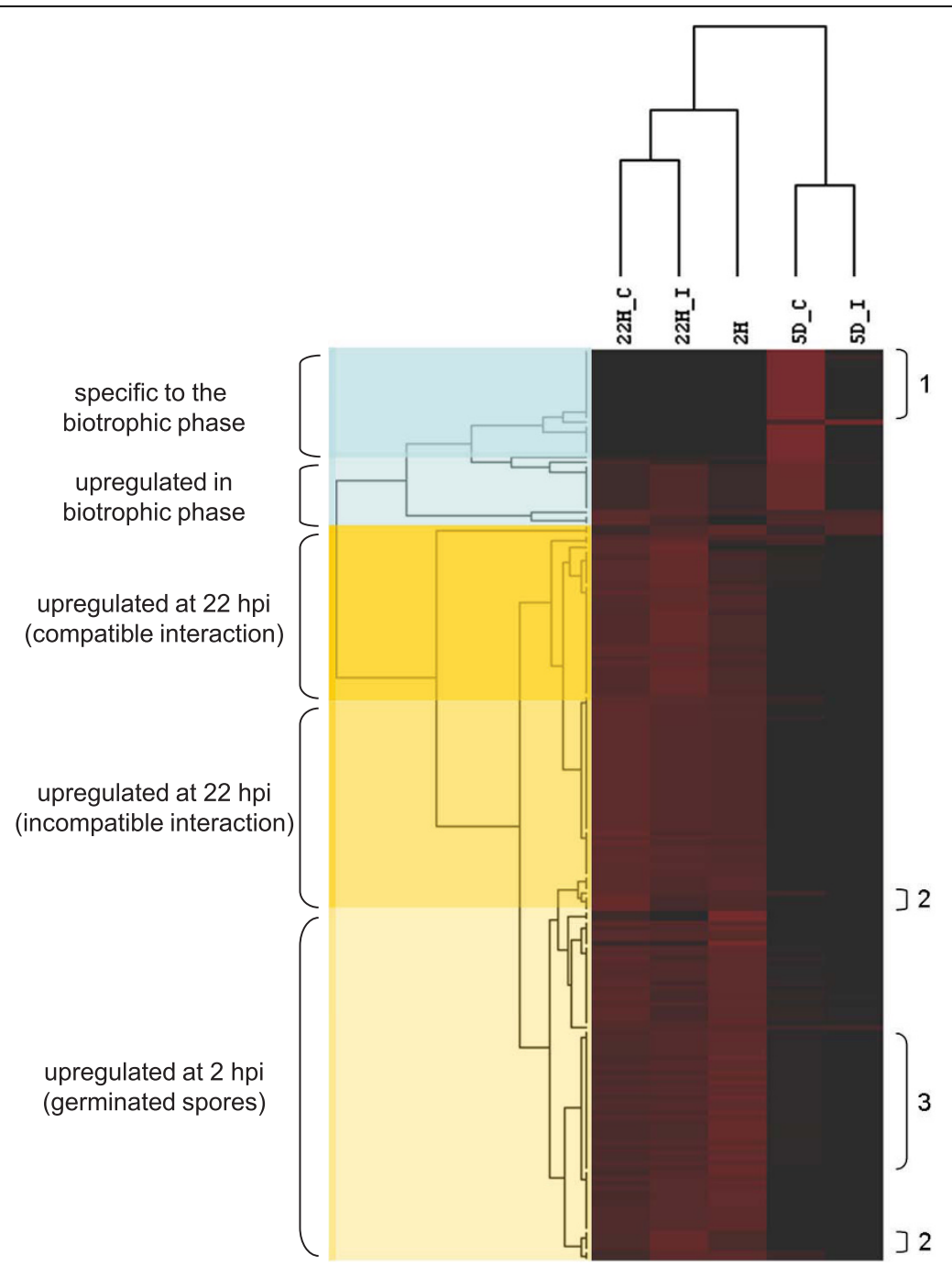

Figure 2 Serial analysis of gene expression: stage-specificity of putative secretome members of the Melampsora unisequence dataset Similarities in serial analysis of gene expression (SAGE) patterns of 182 putative secretome members of the Melampsora unisequence dataset were determined using an average linkage hierarchical clustering according to the Spearman Rank Correlation. Corresponding tags were identified as described in the Methods section. Each row represents a tag, whereas each column corresponds to a SAGE library. 22H_C: 22 hours after inoculation (compatible interaction); $22 \mathrm{H} \_$l: 22 hours after inoculation (incompatible interaction); $2 \mathrm{H}: 2$ hours after inoculation (germinating spores); 5D_C: 5 days after inoculation (compatible interaction); and 5D_l: 5 days after inoculation (incompatible interaction). Genes upregulated during the biotrophic or pre-biotrophic stages are highlighted in blue and yellow, respectively. Medium blue = genes specific to the biotrophic stage; Light blue = genes upregulated during the biotrophic stage; Dark yellow = genes upregulated in 22H_l; Medium yellow = genes upregulated in 22H_C; and Light yellow = genes upregulated in $2 \mathrm{H}$. The relative abundance of the SAGE tag in the library correlates with the intensity of the red color (black, not present; intense red, highly abundant). Brackets indicate clades containing homologues of haustorially expressed secreted proteins (HESPs) 735, 417, and 379, respectively.

expression patterns were consistent with observations made in our libraries, with $60 \%$ of the represented haustorium-enriched library unisequences being upregulated during the biotrophic stage. Compatible and incompatible treatments were grouped together at each time point, and the pre-biotrophic stage libraries were clustered together and separated from the biotrophic stage libraries. Even though similar stage specificity has been observed for the non-secreted counterpart (data not shown), the abundance of tags pointed towards higher expression levels for secreted proteins during the prebiotrophic stage when compared to the rest of the transcriptome. On the other hand, secretome members found during the biotrophic stage had expression levels similar to their non-secreted counterpart (Additional File 3). The mean number of tags per unisequences correlated well with the abundance of clones per contig. While the haustorium-enriched library shared a 
somewhat similar number of genes encoding putative secreted proteins when compared to other libraries, their level of expression, as reflected by the percentage of identified sequences, was quite lower (Additional File 4). Secreted proteins accounted for $25 \%$ of ex planta libraries (from 15.3 to $33.0 \%$ ), while it was only $6.8 \%$ for the haustorium-enriched library. Secretory activity among obligate biotrophs thus appears limited and strongly regulated. A strict control of the secretory activity is required to form the interface layers that are observed in biotrophic interactions [59] and this could be a component of the pathogen's strategy to evade recognition by host factors [19].

\section{Evolutionary constraints of the poplar leaf rust secretome: adaptive evolution}

None of the effectors described from various fungi are known to have close homologues beyond species or genus boundary [27]. In order to determine if the evolutionary model of poplar leaf rust $\mathrm{S}+$ proteins was confined to the presence/absence pattern observed above, we generated new BLASTP searches using 6033 (5349 NS/684 $\mathrm{S}_{+}$) predicted ORFs against the translated gene models of $P$. graminis $\mathrm{f}$. sp. tritici, and plotted the percentage of identity of each dataset to their closest homologues (Figure 3). Around $40 \%$ of each dataset had homologues in the P. graminis f. sp. tritici genome, a proportion that could be explained by the relatively short length of many ORFs, the presence of false ORFs predicted from non-coding regions such as UTRs, and the relative divergence expected between these genera [60]. However, approximately half of NS-predicted ORFs had high identity values (more than 70\%) with their closest homologue from the $P$. graminis $\mathrm{f}$. sp. tritici gene models compared to only $7 \%$ of $\mathrm{S}+$-predicted ORFs, thus suggesting that the secretome is under different evolutionary constraints. Again, fast evolution of coding regions due to molecular arms races between pathogens and hosts might explain the high divergence between orthologues or the absence of close homologues in related species.

We used reciprocal TBLASTX searches (E-value $\leq 1 \mathrm{e}-$ 30) among our taxonomic cDNA libraries to identify orthologues and/or paralogues in different Melampsora species libraries and to classify them into homologous gene groups (HGGs). In order to increase the number of HGGs, we included the gene models from P. graminis f. sp. tritici. We found 369 HGGs consisting of at least three different sequences with a minimum of two Melampsora unisequences retrieved. These HGGs included 1159 Melampsora unisequences and 437 P. graminis $\mathrm{f}$. sp. tritici gene models. HGGs were divided to 283 nonsecreted HGGs (76.7\%) and 86 secreted HGGs (23.3\%) according to their predicted localization. Consistent

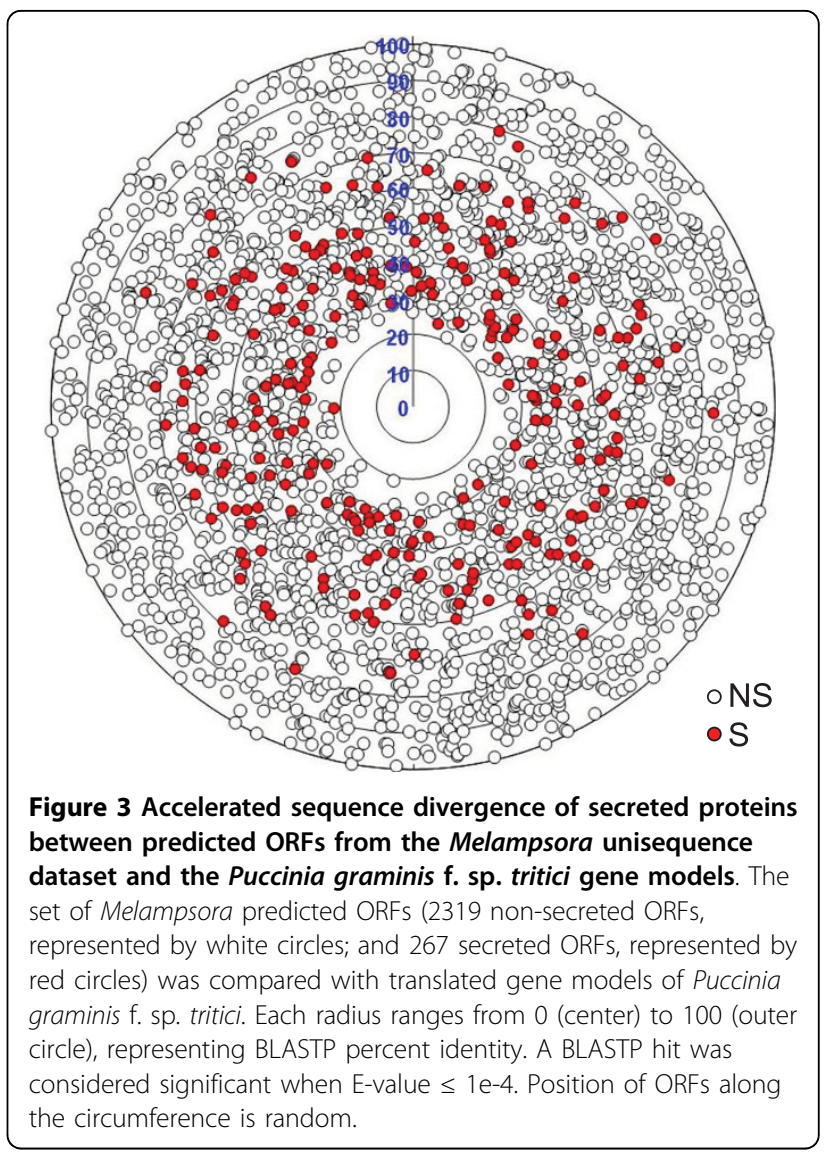

with the above similarity searches, approximately $45 \%$ of secreted HGGs had no P. graminis f. sp. tritici homologues (at E-value $\leq 1 \mathrm{e}-30$ ), compared with $12 \%$ for nonsecreted HGGs. Moreover, the proportion of secreted HGGs (23.3\%) was twice the proportion of S+ unisequences $(11.4 \%)$, and the mean number of Melampsora unisequences per HGG was slightly higher in secreted HGGs (4.3 unisequences/HGG) compared with nonsecreted HGGs (2.9 unisequences/HGG). These results could suggest that a larger proportion of allelic forms and/or paralogue families exist among the rust secretome, which is consistent with an extensive sequence diversification motivated by the coevolutionary arms race [30].

In order to visualize the evolutionary relationships between Melampsora and other fungi we used SimiTri [61], which plots in two-dimensional space the relative similarities of gene sequences between one group (Melampsora) and three comparators. For each sequence included in an HGG, a BLASTX was performed against three other basidiomycetes for which genome sequences were available: Puccinia (Pucciniomycotina; Pucciniomycetes), the wheat stem rust, which is phylogenetically close to Melampsora and shares a similar biotrophic lifestyle; Sporobolomyces 
(Pucciniomycotina; Microbotryomycetes), a free-living saprobic yeast that is phylogenetically close to rusts but differs in its saprophytic lifestyle; and Ustilago (Ustilaginomycotina; Ustilaginomycetes), the corn smut, which is phylogenetically more distant from Melampsora but is also a plant pathogen. In a few cases, sequences within HGGs matched different paralogous sequences in one of the comparators (usually Puccinia). Consensus sequences were thus created from sequences having identical BLASTX hits in the three comparators, allowing multiple consensus sequences for a single HGG. SimiTri was used to plot 417 consensus sequences from 369 Melampsora HGGs against related species' gene models (Figure 4). For each HGG, most Melampsora sequences grouped slightly towards Puccinia, its closest relative (Figure 4). Again, the difference between nonsecreted and secreted HGGs was striking with $69.8 \%$ of non-secreted HGGs exhibiting homologous sequences in the three comparators, while only $33.0 \%$ of secreted HGGs had such homologues. Even tough the percentage of secreted HGGs with no hit in the three other species (16.0\%) was almost four times the percentage of unique non-secreted HGGs (4.2\%), this was not sufficient to explain this difference. The percentage of HGGs unique to Pucciniales was twice higher for secreted HGGs (29.2\% compared with $13.8 \%$ ). Similar secreted/nonsecreted HGGs ratios were observed for the percentage of secreted HGGs absent from Ustilago (11.3\% compared with 5.1\%) or from Sporobolomyces $(9.4 \%$ compared with 4.5\%). While HGGs absent from Ustilago but found in both Puccinia and Sporobolomyces could have been eliminated following the Ustilaginomycotinal Pucciniomycotina radiation, HGGs absent from the freeliving Sporobolomyces but found in the more distant Ustilago could represent genes involved in host-pathogen interactions and/or biotrophic lifestyles. Similarly, recent observations on the whole genome sequences of Ustilago maydis and Laccaria bicolor suggested that the inventory of certain enzymes underwent massive gene loss as a result of its adaptation to a biotrophic ( $U$. maydis) or symbiotic lifestyle (L. bicolor) [40,62].

Molecular genetic analysis of plant-pathogen interactions includes many layers of antagonistic coevolution. Investigation of molecular evolution at these various levels usually reveals diversifying selection and the selective maintenance of variation, resulting in positive selection at the genomic interfaces of escalating attack and defense systems [63]. Following this idea, one of the most reliable indicators of positive selection at the molecular level is a higher non-synonymous nucleotide substitution rate $\left(d_{\mathrm{N}}\right)$ than the synonymous nucleotide substitution rate $\left(d_{\mathrm{S}}\right)$ between two protein-coding DNA sequences (ratio $\omega=d_{\mathrm{N}} / d_{\mathrm{S}}>1$ ) [64]. Based on this criterion, statistical methods, such as the approximate (counting) and the maximum likelihood (ML) methods, have been developed [65-67]. We calculated the $d_{\mathrm{N}}$ and

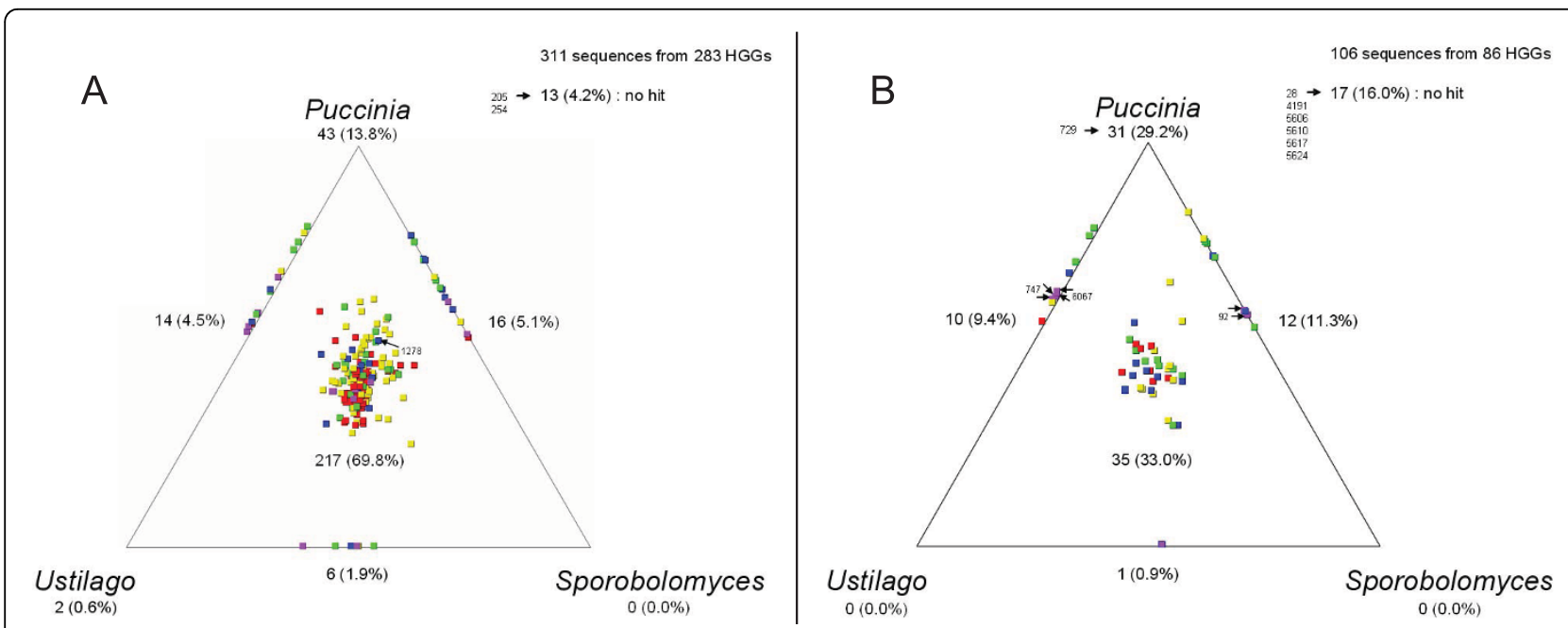

Figure 4 Similarity of Melampsora homologous gene groups (HGGs) to the proteomes of other basidiomycetes. Similarity of Melampsora A) non-secreted and B) secreted homologous gene groups (HGGs) to the proteomes of Puccinia graminis $\mathrm{f}$. sp. tritici, Ustilago maydis and Sporobolomyces roseus. For each of the 369 Melampsora HGGs, a BLASTX search was performed against the proteomes of the other three species and SimiTri was used to plot the sequence similarity relationships between 417 consensus sequences derived from these HGGs and related species. Each tile in the graphics represents a unique consensus sequence and its relative position is computed from the raw BLAST scores derived above (with a cutoff of $>40$ ). Hence, each tile's position indicates its degree of sequence similarity to each of the three selected databases. Sequences showing similarity to only one database are not shown. Sequences showing sequence similarity to only two databases appear on the lines joining the two databases. The position of positively selected HGGs is indicated by arrows. Tiles are colored by their highest BLASTX score for each of the databases: red $\geq 300$; yellow $\geq 200$; green $\geq 150$; blue $\geq 100$; and purple $<100$. 
$d_{\mathrm{S}}$ rates across all possible pairwise sequence comparisons within each of the 369 HGGs using the ML method. The distribution of omega ratios $(\omega)$ was skewed towards extreme low values for non-secreted HGGs, with almost $75 \%$ of highest pairwise estimates of $\omega<0.2$ and only $5 \%>0.8$ (Figure 5). This distribution was quite different for secreted HGGs, with proportions around $40 \%$ and $20 \%$ of highest pairwise estimates of $\omega$ $<0.2$ and $>0.8$, respectively. For $13 \mathrm{HGGs}$, the $d_{\mathrm{N}}$ value was significantly greater than $d_{\mathrm{S}}\left(\omega=d_{\mathrm{N}} / d_{\mathrm{S}}>1.2\right)$ in at least one pairwise comparison (Table 3 ). Ten of these groups under positive selection were secreted HGGs (corresponding to $12 \%$ of the total secreted HGGs). Using a different approach based on Fixed-Effect Likelihood (FEL) statistics, Feau and colleagues detected positive selection in seven gene groups (including five putative secretome members) from a similar dataset [68]. Two of these seven gene groups corresponded to secreted HGGs unravelled using the $d_{\mathrm{N}} / d_{\mathrm{S}}$ approach described here (92 and 6067, corresponding to MEL_49 and MEL_55, respectively, in [68]). Interestingly, eight positively selected secreted HGGs were found to encode cysteine-rich proteins with an even number of Cys residues that may be involved in disulfide bonds. An even number of Cys residues is generally indicative of the presence of disulfide bonds, which are formed between the thiol groups of cysteines. Disulfide bonds play an important role in the folding and stability of some proteins, usually proteins secreted to the extracellular medium, and are typical features of a subset of fungal and oomycete effectors, especially those acting in the plant apoplast [11,27].

To identify additional HGGs under positive selection and detect the amino acid residues that are under positive selection, we contrasted the M2A/M1A, M8/M7 and M8/M8A models with likelihood ratio tests (Additional Files 5 and 6; see Methods) [64,66]. Significant evidence of positive selection was found in 4 (including 2 secreted HGGs) of the 369 HGGs. Selective pressures had previously been identified for one of these secretome members using FEL statistics and a population genetics approach $[68,69]$. This particular secreted HGG has homology with HESP-417 from M. lini, a gene known to be expressed in haustoria and encoding a secreted protein with an even number of Cys residues [26].

We assessed the position of positively selected HGGs on above SimiTri plots (indicated by arrows, Figure 4): only one non-secreted HGG (1278) had homologues in the three databases, two secreted HGGs (747 and 6067)

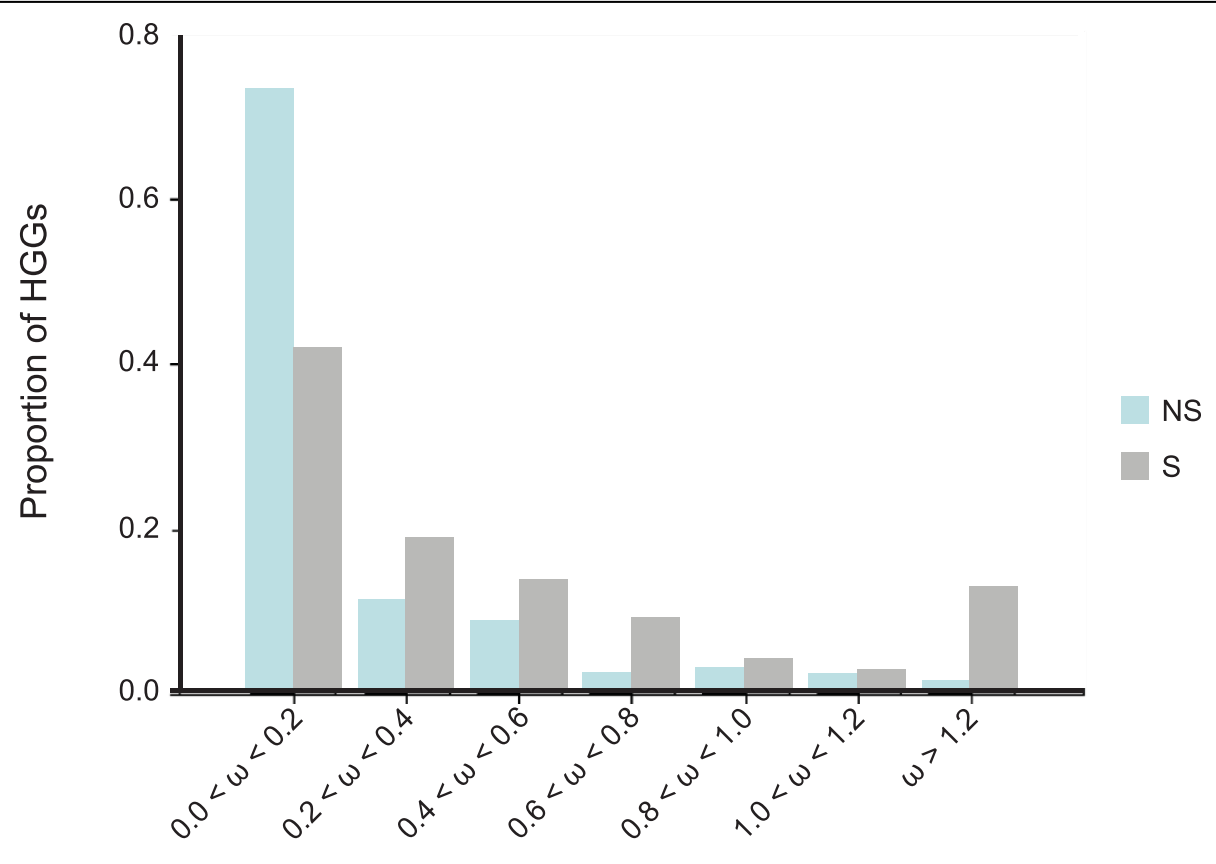

Highest omega ratios $\left(\omega=d_{N} / d_{S}\right)$ among pairwise comparisons

Figure 5 Elevated $d_{\mathrm{N}} / d_{\mathrm{S}}$ ratios among Melampsora homologous gene groups (HGGs) encoding secreted proteins. The rates of nonsynonymous nucleotide substitutions per non-synonymous site $\left(d_{N}\right)$ and the rates of synonymous nucleotide substitutions per synonymous site $\left(d_{s}\right)$ were calculated across all possible pairwise comparisons within each of the 369 HGGs using the maximum likelihood method implemented in the codeml program (runmode $=-2$ ) in the PAML 4 software package. The distribution of highest calculated $\omega\left(d_{N} / d_{S}\right.$ ratios) among all pairwise comparisons within each HGG is shown. In cases where $d_{N}>0$ and $d_{S}=0$ (i.e. $\omega=\infty$ ), the second higher ratio was selected. 
Table 3 Characteristics of the Melampsora homologous gene groups (HGGs) predicted to be under positive selection (at least one pairwise $\omega=d_{N} / d_{S}>1.2$ )

\begin{tabular}{|c|c|c|c|c|c|c|c|c|c|}
\hline HGG & $\mathrm{NS} / \mathrm{S}^{\mathrm{a}}$ & Length & $\begin{array}{l}\text { BLASTX } \\
\text { Fungi UniProtKB }\end{array}$ & E-value & $\begin{array}{l}\text { BLASTX } \\
\text { Puccinia }\end{array}$ & E-value & PFAM & Cys & $\omega^{b}$ \\
\hline 205 & NS & 115 & No hit & & No hit & & - & ND & 2.68 \\
\hline 254 & NS & $200-202$ & No hit & & PGTT03363 & $1 e-10$ & - & ND & 2.59 \\
\hline 1278 & NS & $173-175$ & $\begin{array}{l}\text { XP_001211022 conserved hypothetical protein } \\
\text { [Aspergillus terreus] }\end{array}$ & $3 e-07$ & PGTT11073 & $1 e-34$ & - & ND & 1.88 \\
\hline 28 & $\mathrm{~S}$ & 161 & No hit & & No hit & & - & 0 & 1.38 \\
\hline 92 & S & $271-276^{c}(227)^{d}$ & $\begin{array}{l}\text { AAS45284 proline-rich antigen } \\
\text { [Chrysosporium lucknowense] }\end{array}$ & $4 e-09$ & PGTT01207 & $2 e-13$ & CFEM & $6(2)^{d}$ & 1.43 \\
\hline 729 & S & 269 & $\begin{array}{l}\text { EAT81533 hypothetical protein } \\
\text { [Phaeosphaeria nodorum] }\end{array}$ & $7 e-11$ & PGTा12331 & $7 e-61$ & - & 8 & 1.32 \\
\hline 747 & S & 163 & $\begin{array}{l}\text { XP_757360 hypothetical protein } \\
\text { [Ustilago maydis] }\end{array}$ & $1 e-04$ & PGTT02151 & $2 e-14$ & - & 4 & 1.95 \\
\hline 4191 & S & 129 & No hit & & No hit & & - & 4 & 1.57 \\
\hline 5606 & S & $119-123^{\mathrm{e}}$ & No hit & & No hit & & - & 6 & 1.76 \\
\hline 5610 & S & 98 & No hit & & No hit & & - & $6^{9}$ & 4.31 \\
\hline 5617 & $\mathrm{~S}$ & $168-169^{f}$ & No hit & & No hit & & - & $0^{g}$ & 1.23 \\
\hline 5624 & $S$ & 176 & No hit & & No hit & & - & 8 & 1.93 \\
\hline 6067 & S & 285 & $\begin{array}{l}\text { XP_758577 hypothetical protein } \\
\text { [Ustilago maydis] }\end{array}$ & $6 e-06$ & PGTT13234 & $5 e-21$ & - & $10^{g}$ & 1.27 \\
\hline
\end{tabular}

BLASTX and PFAM hits were considered significant when E-value $\leq 1 e-4$ and $1 e-5$, respectively.

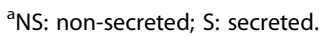

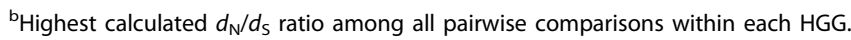

'Length is 271 (M. medusae f. sp. deltoidae, M. medusae f. sp. tremuloidae and M. occidentalis), and 276 (M. larici-populina); an 86 amino acids insertion and a 5 amino acids minisatellite are also present in a M. medusae f. sp. deltoidae unisequence (length: 357 ) and a M. larici-populina unisequence (length: 281), respectively.

${ }^{\mathrm{d}} \mathrm{A} 44$ amino acids deletion (including 4 Cys residues) is present in a M. medusae f. sp. deltoidae unisequence.

e Length is 119 (M. medusae f. sp. tremuloidae) and 123 (M. occidentalis).

${ }^{\mathrm{f}} \mathrm{A} 12$ amino acids minisatellite is present in a $M$. occidentalis unisequence (length: 181).

${ }^{g}$ Additional Cys residues are present before the signal peptide cleavage site.

were absent from Sporobolomyces, one secreted HGG (92) was absent from Ustilago, one secreted HGG (729) was present only in Puccinia, and the remaining HGGs (6 secreted and 2 non-secreted HGGs) had no hit. Two other groups of sequences identified using FEL statistics [68] had corresponding HGGs plotted on the line between Puccinia and Ustilago (absent from Sporobolomyces) (data not shown).

\section{Conclusion}

Database searches with sequences of small secreted proteins from fungi commonly do not yield homologues or known protein domains, the only recognizable features being the presence of a signal peptide for secretion and, in many cases, an even number of cysteine residues. Despite these commonalities, effectors appear to be evolutionarily diverse and highly variable in their distribution, showing very limited phylogenetic distributions possibly due to accelerated evolution stimulated by plant-pathogen arms races [27]. In a straightforward in silico approach, we generated a first overview of the secretome from poplar leaf rusts belonging to the genus Melampsora, unravelling an unknown and diversifying set of genes. The identification of positive selection in putative secreted proteins reported here suggests that these genes are likely to encode candidate effectors implicated in host-pathogen interactions. Such information should be used to augment other selection criteria (such as gene expression data) for prioritizing candidate effector genes for functional studies. Two intriguing properties of rust fungi are their host specificity and their need for host alternation. Even though host specificity is probably controlled at several levels, examples from the flax rust fungus suggest that the secretion of effectors plays a prominent role [26]. Their intimate interactions with host factors expose them to very strong selective pressures resulting in their rapid evolutionary turnover. However, poplar leaf rust effectors not only cope with the poplar defense machinery, they also face another phylogenetically diverse host plant, which differs between species, from other dicots to monocots and even gymnosperms. Is this particularity responsible for a greater sequence diversification? Or is it responsible for a broader arsenal of effectors in poplar leaf rusts? The recent completion of the M. larici-populina genome http://genome.jgi-psf.org/Mellp1/Mellp1.home. 
html will reveal further information on the whole repertoire of secreted proteins in this pathogen. Comparative genomics studies with other biotrophs should elucidate molecular mechanisms underlying common strategies to infect plants. The identification of host targets will provide further insight into the evolutionary forces that shaped the rust secretome, a key step facilitated by the availability of the poplar genome sequence [70] and transcript profiling of poplar-rust interactions [55,71,72]. This pathosystem clearly represents an unprecedented opportunity to understand the particularities of hostpathogen interactions.

\section{Methods}

\section{Rust and plant material}

cDNA libraries were constructed from ex planta material (resting and germinating urediniospores, germ tubes, etc.) of four different Melampsora taxa. Fungal materials from isolates of the North American subspecies $M$. medusae f. sp. deltoidae and the Eurasian species $M$. larici-populina were harvested from naturally infected leaves of eastern cottonwood (Populus deltoides) and hybrid poplar (P. balsamifera $\times$ P. maximowiczii) clones, respectively. Melampsora medusae f. sp. tremuloidae and M. occidentalis mono-uredinial cultures were used to inoculate fresh leaves of $P$. tremuloides and $P$. trichocarpa, respectively. Inoculated leaves were maintained for 13 days in a growth chamber at $60 \%$ humidity, $19^{\circ} \mathrm{C}$ and $16 \mathrm{~h}$ photoperiod. In addition, we generated one additional haustorium-enriched library (biotrophic stage) for the M. larici-populina species. Haustoria were isolated by affinity chromatography as described by Hahn and Mendgen [73]. A mixture of plant leaf and fungal tissues was collected 6 days after inoculation of a rust-susceptible P. $\times$ jackii clone 1014 with the rust strain $M l p$ Berth. 3729. A $100-\mu \mathrm{m}$ pore size nylon mesh was used to remove the bulk of the plant cell material from the crude preparation, which was then passed through an $11-\mu \mathrm{m}$ pore size nylon mesh to remove intact plant cells. An affinity column was prepared by covalently attaching concanavalin A (Pharmacia Biotech) to cyanogen bromide-activated Sepharose 6 MB (Pharmacia Biotech) as described in the manufacturer's protocol. Samples of purified haustoria colored using Calcofluor white $(50 \mu \mathrm{M}$ final concentration) were then examined using a fluorescence microscope under UV filters.

\section{cDNA libraries and DNA sequencing}

Haustoria samples were pelleted by centrifugation at $20,800 \mathrm{~g}$, washed twice with sterile distilled water, and maintained at $-80^{\circ} \mathrm{C}$ until total RNA extraction. Fungal material was directly frozen in liquid nitrogen and ground using the Mixer Mill MM 300 with $2 \mathrm{~mm}$ tungsten carbide beads. All the following manipulations were performed according to the manufacturer's instructions. Total RNA was extracted from ex planta material and purified haustoria using the RNeasy mini kit (Qiagen, Valencia, CA, USA) and the Absolutely RNA ${ }^{\circ}$ miniprep kit (Stratagene, La Jolla, CA, USA), respectively. PolyA RNA was purified using biotylinated oligo-dT/ streptavidin-coated magnetic beads (Dynabeads ${ }^{\bullet}$ Oligo $(\mathrm{dT})_{25}$; Dynal Biotech, Oslo, Norway). Haustoriumenriched M. larici-populina as well as M. medusae f. sp. tremuloidae and $M$. occidentalis ex planta cDNA libraries were generated using the SMART ${ }^{\mathrm{Tm}} \mathrm{cDNA}$ library construction kit (Clontech, Mountain View, CA, USA). Melampsora larici-populina and M. medusae f. sp. deltoidae ex planta cDNA libraries were constructed using the pBlueScript II XR cDNA library construction kit (Stratagene) according to the manufacturer's instructions. Following the column sepharose chromatography step included in the protocol, only size fractions above $500 \mathrm{bp}$ were retained for ligation in the SfiI-digested, dephosphorylated pDNR-LIB vector. Plasmid ligations were transformed by electroporation into E. coli ElectroMAXTM DH10BTM Cells (Invitrogen, Carlsbad, CA, USA). After library amplification and tittering, individual colonies were transferred onto 384-well microtiter plates containing LB medium with $30 \mu \mathrm{g} / \mathrm{ml}$ chloramphenicol for PCR amplification and sequencing. cDNA inserts were amplified according to the manufacturer's PCR protocol and then sequenced with the M13 forward primer (5'-GTAAAACGACGGCCAGT-3') using the Big Dye Terminator Cycle Sequencing Kit v1.1 on an ABI 3730xl sequencer (Applied Biosystems) at the CHUQ Research Centre (CRCHUQ) Sequencing and Genotyping Platform, Quebec City, QC, Canada. Sequences were deposited at NCBI under accession numbers GW672673 to GW687576.

\section{CDNA assembly and ORF prediction}

Raw sequences were trimmed and cleaned using the Phred software [74], which resulted in the identification and removal of poor quality regions (quality cutoff of 20). Cross-match was then used to mask vector sequence in each read (minimum match of 10, minimum score of 20). The extent of redundancy for each library was ascertained using the Phrap software (Phil Green, http://www.phrap.org), which was also used to compile the unisequence set (minimum match of 50 , minimum score of 100). In order to identify and remove plant sequences in the ESTs, unisequences were used in BLAST comparisons against the Populus trichocarpa genome and predicted gene models. Initial ORF prediction for Melampsora spp. was generated with the bestORF algorithm (Softberry) using Ustilago parameters. 


\section{Sequence analysis}

Similarity searches for full length sequences and conserved domains were performed using a combination of standard bioinformatics programs and customized Python scripts. Each assembled transcript was searched against UniProtKB database (Release 15.5, TrEMBL and Swiss-Prot at http://www.uniprot.org) resources [75] using the BLASTX algorithm [76]. Using UniProt/Gene Ontology (GO) crossed tables, candidate GO assignments were predicted on the basis of best transcripts matches (E-value $<10^{-05}$ ) to the UniProt reference sequences. Categories were assigned on the basis of the biological, functional and molecular annotations available from GO http://www.geneontology.org[46].

Additionally, we constructed and searched (using the BLASTX algorithm) two other fungal sequence databases. The BasidiomycotaDB database included Basidiomycota (excluding Pucciniales) protein sequences from the non-redundant database of NCBI $(124,751$ sequences), a 6 -frame translation of Basidiomycota (excluding Pucciniales) EST sequences from NCBI (287,259 sequences), and gene models from eight genome projects: Coprinus cinereus Okayama 7 (\#130) (Broad Institute); Cryptococcus neoformans var. grubii serotype A, strain H99 (Broad Institute); Laccaria bicolor S238N-H82 (JGI); Malassezia globosa CBS 7966 (Procter and Gamble Co.); Phanerochaete chrysosporium RP78 (JGI); Postia placenta MAD-698 (JGI); Sporobolomyces roseus IAM 13481 (JGI); and Ustilago maydis 521 (Broad Institute) (a total of 85,025 gene models). The PuccinialesDB database included Pucciniales protein sequences from the non-redundant database of NCBI (390 sequences), a 6-frame translation of Pucciniales EST sequences from NCBI (84,006 sequences), and gene models from P. graminis f. sp. tritici CRL 75-36-700-3 (20,567 gene models). The hmmpfam program (HMMer software; http://hmmer.janelia.org[77] was used to search the PFAM HMM profile database of protein domains [45].

\section{Signal peptide prediction}

In silico predictions of secreted proteins were carried out using a combination of SignalP 3.0, TargetP 1.1 and TMHMM $2.0[44,78,79]$. The SignalP algorithms incorporate a cleavage site and signal peptide prediction based on artificial neural networks (NN) and hidden Markov models (HMM). In order to support the SignalP results and exclude proteins with either mitochondrial targeting peptides or transmembrane domains, protein sequences were also entered into different prediction servers. TargetP is a neural networks server that predicts the subcellular localization of eukaryotic proteins based on the presence of any of the N-terminal presequences, either chloroplast transit peptide (for plant predictions), mitochondrial targeting peptide or secretory pathway signal peptide, while TMHMM uses hidden Markov models for the prediction of transmembrane helices. Following predictions, the output files were manipulated to select signal peptides containing sequences using the following criteria: (1) positive SignalP-HMM Sprob score, (2) positive SignalP-NN Smax and D scores, (3) TargetP signal peptide prediction, and (4) no transmembrane domains. SignalP-HMM Sprob score was selected because of its ability to discriminate between $\mathrm{N}$-terminal signal peptides and $\mathrm{N}$-terminal signal anchors, while SignalP-NN Smax and D scores are the most accurate single scores [80]. Furthermore, because TMHMM may not distinguish signal peptides from transmembrane domains, deduced proteins with a single transmembrane domain within 40 amino acids of the $\mathrm{N}$-terminus were also considered as potential secreted proteins.

\section{SAGE analyses}

The SAGE method was used as initially described in Velculescu et al. [81,82] at the CHUQ Research Centre (CRCHUQ) SAGE Platform, Quebec City, QC, Canada http://www.crchuq.ulaval.ca/plateformes/gpb. Fungal materials from $M$. larici-populina strain $M l p$ Berth. 3729 were harvested from both susceptible $(P . \times$ jackii) and resistant $(P$. trichocarpa $\times P$. deltoides 'Boelare') hosts at two different time points ( 22 hours and 5 days) after inoculation. Additionally, germinating urediniospores and germ tubes were collected 2 hours after inoculation on the susceptible cultivar by painting leaves with $5 \%$ cellulose acetate (dissolved in acetone), letting the acetone evaporate, and stripping the cellulose acetate film off the leaves. For each of the five treatments, 50 micrograms total RNA were extracted using the RNeasy mini kit (Qiagen, Valencia, CA, USA) and poly (A) RNA isolated with the mRNA Mini kit (Qiagen), annealed with the biotin-50-T18-30 primer, and converted into cDNA using the cDNA synthesis kit (Invitrogen, Carlsbad, CA, USA). The resulting cDNA were digested with NlaIII (anchoring enzyme), and the 3 ' restriction fragments were isolated with streptavidincoated magnetic beads (Dynal Biotech, Oslo, Norway) before being separated into two populations. Each population was ligated to one of the two annealed linker pairs and washed to remove unligated linkers. The tag beside the most 3' NIaIII restriction site (CATG) of each transcript was released by digestion with BsmFI (tagging enzyme). The blunting kit from Takara Co. (Otsu, Japan) was used for the blunting and ligation of the two tag populations. The resulting ligation products containing the ditags were amplified by PCR with an initial denaturation step of $1 \mathrm{~min}$ at $95^{\circ} \mathrm{C}$, followed by 22 cycles of $20 \mathrm{sec}$ at $94^{\circ} \mathrm{C}, 20 \mathrm{sec}$ at $60^{\circ} \mathrm{C}$ and $20 \mathrm{sec}$ at $72^{\circ} \mathrm{C}$ with $27 \mathrm{bp}$ primers. The PCR products were then 
digested with NlaIII and the band containing the ditags was extracted from $12 \%$ acrylamide gel. The purified ditags were self-ligated to form concatemers of 5001800 bp isolated by agarose gel. The resulting DNA fragments were ligated into the SphI site of pUC19 and cloned into UltraMAX DH5aFT E. coli cells (Invitrogen, Carlsbad, CA, USA). White colonies were screened by PCR to select long inserts for automated sequencing as previously described for cDNA libraries.

Sequence files were analyzed using the SAGEparser program [83]. Tags corresponding to linker sequences were discarded and duplicate concatemers were counted only once. To identify the transcripts, the sequences of 15 bp SAGE tags (NlaIII site CATG plus adjacent $11 \mathrm{bp}$ tags) were matched with a collection of unassembled poplar and M. larici-populina ESTs with polyA tail using a customized Python script. To avoid the possibility of sequencing errors in the EST database, the matches that were identified only once among the EST database were not considered.

\section{Positive selection analyses}

Homologous gene groups (HGGs) were identified from reciprocal TBLASTX searches $(\mathrm{E}$-value $<1 \mathrm{e}-30)$ between libraries and $P$. graminis f. sp. tritici gene models followed by graph clustering analysis using a TCL implementation of the Deep-First Search algorithm. Each HGG included at least two sequences from Melampsora unisequences and a minimum of three total sequences. HGGs were either removed or divided when overlapping regions where too short or when similarity was not found throughout the majority of the unisequence coding sequences. Furthermore, sequences with gaps across the aligned coding sequences were removed in order to minimize the impact of the pitfalls of positive selection analyses, such as gap-induced misalignments and relaxed selection in pseudogenes. The resulting 369 HGGs were then submitted to positive selection analyses using a suite of program grouped into a single Python script. The protein sequences in each HGG were first aligned with ClustalW [84] and the corresponding coding DNA sequences were automatically extracted. A Neighbor-joining phenetic tree based on distance matrix between nucleotidic sequences was then reconstructed for each HGG and used as starting tree for Bayesian inference and Markov Chain Monte Carlo simulations (B/MCMC) (only possible with HGG of 4 sequences and more; the Neighborjoining tree reconstructed with PAUP* was used for HGG of 3 sequences). Prior to the B/MCMC, the models for nucleotide substitutions were selected using the hierarchical likelihood ratio test (hLRT) implemented in the Modeltest 3.7 program. Adaptive evolution was first estimated by pairwise calculation of the rates of nonsynonymous nucleotide substitutions per nonsynonymous site
$\left(d_{\mathrm{N}}\right)$ and the rates of synonymous nucleotide substitutions per synonymous site $\left(d_{\mathrm{S}}\right)$ between all members of an HGG. Additionally, as adaptive evolution is likely to act on a small subset of amino acid residues and hence averages of substitution rates across the gene may not strictly indicate positive selection, HGGs were scanned for adaptive evolution using codon-based substitution models that allow $\omega$ to vary among sites, with the parameters of the model estimated using maximum likelihood. These analyses were conducted using the codeml application from the PAML package version 4 [67]. Bayesian inference of phylogeny aimed at estimating the posterior probabilities and branch length of phylogenetic trees as starting values for codeml maximum likelihood iteration under codon model M0 to get fixed branch lengths. The resulting $\omega$ pairwise calculations are shown in Table 3 for all HGGs with at least one pairwise calculation showing $\omega>1.2$. We also contrasted the codon substitution models M1A (neutral), M2A (selection), M7 (beta), M8 (beta and $\omega$ ) and M8A (beta and $\omega=1$; [85]). The model M1A assumes two site classes in proportions $\mathrm{p} 0$ and $\mathrm{p} 1=1$-p 0 with $0<\omega 0<1$ (conserved) and $\omega 1=$ 1 (neutral). M2A adds an additional class of site with $\omega 2$ as a free parameter, allowing for sites with $\omega 2>1$ with proportion p2. Model M7 uses a beta distribution of sites within the interval $0<\omega<1$. M8 adds an extra class of sites to the M7 model, allowing for positively selected sites with $\omega>1$, while this extra $d_{\mathrm{N}} / d_{\mathrm{S}}$ category is restricted to one in model M8A [85]. From these models, statistical significance was tested using likelihood ratio tests by comparing the null models M1A, M7 and M8A with the alternative M2A, M8 and M8 models, respectively. Models M2A and M8 are tests of positive selection among codon sites and were implemented with at least three different starting $\omega$ values $(0.2,1.0$ and 2.0). Twice the difference in log likelihood ratio between null and alternative models was compared with a $\chi 2$ distribution with two degrees of freedom. The likelihood ratio tests assess whether the alternative models fits the data better than the null model and is known to be conservative in simulation tests. For HGGs that tested positive using the ML method, posterior Bayesian probabilities of site classes were inferred for each amino acid site by using the Bayes empirical Bayes method [86].

\section{Additional material}

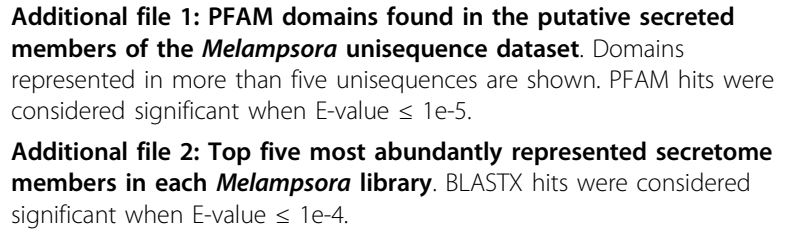

Additional file 1: PFAM domains found in the putative secreted members of the Melampsora unisequence dataset. Domains represented in more than five unisequences are shown. PFAM hits were considered significant when E-value $\leq 1 \mathrm{e}-5$.

Additional file 2: Top five most abundantly represented secretome members in each Melampsora library. BLASTX hits were considered significant when E-value $\leq 1 \mathrm{e}-4$. 


\section{Additional file 3: Mean number of SAGE tags associated with} Melampsora unisequences

Additional file 4: Proportion of contigs and clones included in the putative secretome of Melampsora.

Additional file 5: Characteristics of the Melampsora homologous gene groups (HGGs) predicted to be under positive selection (sitebased analysis with codeml). BLASTX and PFAM hits were considered significant when E-value $\leq 1 \mathrm{e}-4$ and 1e-5, respectively.

Additional file 6: Significant likelihood ratio tests and sites under positive selection as inferred under the site class models $M 1 A$ M2A, M7, M8 and M8A of codeml applied to each of the Melampsora homologous gene groups (HGGs).

\section{Acknowledgements}

This work was supported by the Genomics Research Initiative of Natural Resources Canada to RCH. The authors would like to thank the Broad Institute and the DOE-JGl for releasing the data of the fungal genome sequencing projects. Furthermore, the authors thank Brian Boyle for technical assistance and Josyanne Lamarche, Sébastien Duplessis and Francis Martin for helpful comments on the manuscript.

\section{Author details}

'Natural Resources Canada, Canadian Forest Service, Laurentian Forestry Centre, 1055 du PEPS, P.O. Box 10380, Stn. Sainte-Foy, Québec, QC, GIV 4C7, Canada. ${ }^{2}$ Department of Forest Sciences, Faculty of Forestry, University of British Columbia, Vancouver, BC, V6T 1Z4, Canada. ${ }^{3}$ Unité Mixte de Recherche 1202, Institut National de la Recherche Agronomique-Université Bordeaux I, Biodiversité, Génes et Communautés (BioGeCo), INRA BordeauxAquitaine, 33612 Cestas Cedex, France.

\section{Authors' contributions}

DL contributed to the conception and design of the project, conducted laboratory experiments (EST libraries), designed bioinformatics scripts, performed analysis and interpretation of the data and drafted the manuscript. NF and RCH helped conceive the project and participated in its coordination. NF conducted laboratory experiments (EST libraries and SAGE analysis) and helped design bioinformatics scripts. NF, PT and RCH critically revised the manuscript. All authors read, helped to edit, and approved the final manuscript.

Received: 15 January 2010 Accepted: 8 July 2010 Published: 8 July 2010

\section{References}

1. Cummins GB, Hiratsuka Y: Illustrated genera of the rust fungi St.Paul: APS Press, 32003 .

2. Steenackers J, Steenackers M, Steenackers V, Stevens M: Poplar diseases, consequences on growth and wood quality. Biomass Bioenergy 1996, 10:267-274.

3. Dowkiw A, Bastien C: Characterization of two major genetic factors controlling quantitative resistance to Melampsora larici-populina leaf rust in hybrid poplars: strain specificity, field expression, combined effects, and relationship with a defeated qualitative resistance gene. Phytopathology 2004, 94:1358-1367.

4. Pinon J, Frey P: Interactions between poplar clones and Melampsora populations and their implications for breeding for durable resistance. Rust diseases of willow and poplar Wallingford: CAB InternationalPei MH, McCracken AR 2005, 139-154.

5. Davis EL, Hussey RS, Baum TJ, Bakker J, Schots A, Rosso MN, Abad P: Nematode parasitism genes. Annu Rev Phytopathol 2000, 38:365-396.

6. Davis EL, Hussey RS, Baum TJ: Getting to the roots of parasitism by nematodes. Trends Parasitol 2004, 20:134-141.

7. Alfano JR, Collmer A: Type III secretion system effector proteins: double agents in bacterial disease and plant defense. Annu Rev Phytopathol 2004, 42:385-414.

8. Birch PRJ, Rehmany AP, Pritchard L, Kamoun S, Beynon JL: Trafficking arms: oomycete effectors enter host plant cells. Trends Microbiol 2006, 14:8-11.
9. Ellis J, Catanzariti AM, Dodds P: The problem of how fungal and oomycete avirulence proteins enter plant cells. Trends Plant Sci 2006, 11:61-63.

10. Grant SR, Fisher EJ, Chang JH, Mole BM, Dangl JL: Subterfuge and manipulation: type III effector proteins of phytopathogenic bacteria. Annu Rev Microbiol 2006, 60:425-449.

11. Kamoun S: A catalogue of the effector secretome of plant pathogenic oomycetes. Annu Rev Phytopathol 2006, 44:41-60.

12. Jones JDG, Dangl JL: The plant immune system. Nature 2006, 444:323-329.

13. Kemen E, Kemen AC, Rafiqi M, Hempel U, Mendgen K, Hahn M, Voegele RT: Identification of a protein from rust fungi transferred from haustoria into infected plant cells. Mol Plant Microbe Interact 2005, 18:1130-1139.

14. Catanzariti A-M, Dodds PN, Ellis JG: Avirulence proteins from haustoriaforming pathogens. FEMS Microbiol Lett 2007, 269:181-188.

15. Whisson SC, Boevink PC, Moleleki L, Avrova AO, Morales JG, Gilroy EM, Armstrong MR, Grouffaud S, van West P, Chapman S, Hein I, Toth IK, Pritchard L, Birch PRJ: A translocation signal for delivery of oomycete effector proteins into host plant cells. Nature 2007, 450:115-118.

16. Hahn M, Mendgen K: Signal and nutrient exchange at biotrophic plantfungus interfaces. Curr Opin Plant Biol 2001, 4:322-327.

17. Voegele RT, Mendgen K: Rust haustoria: nutrient uptake and beyond. New Phytol 2003, 159:93-100.

18. Voegele RT: Uromyces fabae: development, metabolism, and interactions with its host Vicia faba. FEMS Microbiol Lett 2006, 259:165-173.

19. Heath MC: Signalling between pathogenic rust fungi and resistant or susceptible host plants. Ann Bot 1997, 80:713-720.

20. Dodds PN, Rafiqi M, Gan PHP, Hardham AR, Jones DA, Ellis JG: Effectors of biotrophic fungi and oomycetes: pathogenicity factors and triggers of host resistance. New Phytol 2009, 183:993-1000.

21. Allen RL, Bittner-Eddy PD, Grenville-Briggs LJ, Meitz JC, Rehmany AP, Rose LE, Beynon JL: Host-parasite coevolutionary conflict between Arabidopsis and downy mildew. Science 2004, 306:1957-1960.

22. Dodds PN, Lawrence GJ, Catanzariti A-M, Ayliffe MA, Ellis JG: The Melampsora lini AvrL567 avirulence genes are expressed in haustoria and their products are recognized inside plant cells. Plant Cell 2004, 16:755-768.

23. Shan W, Cao M, Leung D, Tyler BM: The Avr1b locus of Phytophthora sojae encodes an elicitor and a regulator required for avirulence on soybean plants carrying resistance gene Rps1b. Mol Plant Microbe Interact 2004, 17:394-403.

24. Armstrong MR, Whisson SC, Pritchard L, Bos JIB, Venter E, Avrova AO, Rehmany AP, Böhme U, Brooks K, Cherevach I, Hamlin N, White B, Fraser A, Lord A, Quail MA, Churcher C, Hall N, Berriman M, Huang S, Kamoun S, Beynon JL, Birch PRJ: An ancestral oomycete locus contains late blight avirulence gene Avr3a, encoding a protein that is recognized in the host cytoplasm. Proc Natl Acad Sci USA 2005, 102:7766-7771.

25. Rehmany AP, Gordon A, Rose LE, Allen RL, Armstrong MR, Whisson SC, Kamoun S, Tyler BM, Birch RJB, Beynon JL: Differential recognition of highly divergent downy mildew avirulence gene alleles by RPP1 resistance genes from two Arabidopsis lines. Plant Cell 2005, 17:1839-1850.

26. Catanzariti A-M, Dodds PN, Lawrence GJ, Ayliffe MA, Ellis JG: Haustorially expressed secreted proteins from flax rust are highly enriched for avirulence elicitors. Plant Cell 2006, 18:243-256.

27. Rep M: Small proteins of plant-pathogenic fungi secreted during host colonization. FEMS Microbiol Lett 2005, 253:19-27.

28. Dawkins R, Krebs JR: Arms races between and within species. Proc $R$ Soc Lond B Biol Sci 1979, 205:489-511.

29. Dawkins R: The extended phenotype: the long reach of the gene Oxford: Oxford University Press 1999.

30. Dodds PN, Lawrence GJ, Catanzariti A-M, Teh T, Wang CIA, Ayliffe MA, Kobe B, Ellis JG: Direct protein interaction underlies gene-for-gene specificity and coevolution of the flax resistance genes and flax rust avirulence genes. Proc Natl Acad Sci USA 2006, 103:8888-8893.

31. Rohmer L, Guttman DS, Dangl JL: Diverse evolutionary mechanisms shape the type III effector virulence factor repertoire in the plant pathogen Pseudomonas syringae. Genetics 2004, 167:1341-1360.

32. Schürch S, Linde CC, Knogge W, Jackson LF, McDonald BA: Molecular population genetic analysis differentiates two virulence mechanisms of the fungal avirulence gene NIP1. Mol Plant Microbe Interact 2004, 17:1114-1125. 
33. Liu Z, Bos JIB, Armstrong M, Whisson SC, da Cunha L, Torto-Alalibo T, Win J, Avrova AO, Wright F, Birch PRJ, Kamoun S: Patterns of diversifying selection in the phytotoxin-like scr74 gene family of Phytophthora infestans. Mol Biol Evol 2005, 22:659-672.

34. Ma W, Dong FFT, Stavrinides J, Guttman DS: Type III effector diversification via both pathoadaptation and horizontal transfer in response to a coevolutionary arms race. PLoS Genet 2006, 2:e209.

35. Stergiopoulos I, De Kock MJD, Lindhout P, De Wit PJGM: Allelic variation in the effector genes of the tomato pathogen Cladosporium fulvum reveals different modes of adaptive evolution. Mol Plant Microb Interact 2007, 20:1271-1283.

36. Win J, Morgan W, Bos J, Krasileva KV, Cano LM, Chaparro-Garcia A Ammar R, Staskawicz BJ, Kamoun S: Adaptive evolution has targeted the C-terminal domain of the RXLR effectors of plant pathogenic oomycetes. Plant Cell 2007, 19:2349-2369.

37. Jiang RHY, Tripathy S, Govers F, Tyler BM: RXLR effector reservoir in two Phytophthora species is dominated by a single rapidly evolving superfamily with more than 700 members. Proc Natl Acad Sci USA 2008, 105:4874-4879.

38. van der Merwe MM, Kinnear MW, Barrett LG, Dodds PN, Ericson L, Thrall PH, Burdon JJ: Positive selection in AvrP4 avirulence gene homologues across the genus Melampsora. Proc R Soc Lond Biol Sci 2009, 276:2913-2922.

39. Dean RA, Talbot NJ, Ebbole DJ, Farman ML, Mitchell TK, Orback MJ, Thon M, Kulkarni R, Xu J-R, Pan H, Read ND, Lee Y-H, Carbone I, Brown D, Oh YY, Donofrio N, Jeong JS, Soanes DM, Djonovic S, Kolomiets E, Rehmeyer C, Li W, Harding M, Kim S, Lebrun M-H, Bohnert H, Coughlan S, Butler J, Calvo S, Ma L-J, Nicol R, Purcell S, Nusbaum C, Galagan JE, Birren BW: The genome sequence of the rice blast fungus Magnaporthe grisea. Nature 2005, 434:980-986

40. Kämper J, Kahmann R, Bölker M, Ma L-J, Brefort T, Saville BJ, Banuett F, Kronstad JW, Gold SE, Müller O, Perlin MH, Wösten HAB, de Vries R, Ruiz Herrera J, et al: Insights from the genome of the biotrophical fungal plant pathogen Ustilago maydis. Nature 2006, 444:97-101.

41. Tyler BM, Tripathy S, Zhang X, Dehal P, Jiang RHY, Aerts A, Arredondo FD, Baxter L, Bensasson D, Beynon JL, Chapman J, Damanesco CMB, et al: Phytophthora genome sequences uncover evolutionary origins and mechanisms of pathogenesis. Science 2006, 313:1261-1266.

42. Cuomo CA, Güldener U, Xu J-R, Trail F, Turgeon BG, Di Pietro A, Walton JD, Ma L-J, Baker SE, Rep M, Adam G, Antoniw J, Baldwin T, Calvo S, Chang Y-L, DeCaprio D, Gale LR, Gnerre S, Goswami RS, Hammond-Kosack K, Harris LJ, Hilburn K, Kennell JC, Kroken S, Magnuson JK, Mannhaupt G, Mauceli E, Mewes H-W, Mitterbauer R, Muelbauher G, Münsterkötter M, Nelson D, O'Donnell K, Ouellet T, Qi W, Quesneville H, Roncero MIG, Seong K-S, Tetko IV, Urban M, Waalwijk C, Ward TJ, Yao J, Birren BW, Kistler HC: The Fusarium graminearum genome reveals a link between localized polymorphism and pathogen specialization. Science 2007, 317:1400-1402.

43. Hane JK, Lowe RGT, Solomon PS, Tan K-C, Schoch CL, Spatafora JW, Crous PW, Kodira C, Birren BW, Galagan JE, Torriani SFF, McDonald BA, Oliver RP: Dothideomycete-plant interactions illuminated by genome sequencing and EST analysis of the wheat pathogen Stagonospora nodorum. Plant Cell 2007, 19:3347-3368.

44. Bendtsen JD, Nielsen H, von Heijne G, Brunak S: Improved prediction of signal peptides: SignalP 3.0. J Mol Biol 2004, 340:783-795.

45. Bateman A, Coin L, Durbin R, Finn RD, Hollich V, Griffiths-Jones S, Khanna A, Marshall M, Moxon S, Sonnhammer ELL, Studholme DJ, Yeats C, Eddy SR: The Pfam protein families database. Nucleic Acids Res 2004, 32:D138-D141.

46. The Gene Ontology Consortium: Gene Ontology: tool for the unification of biology. Nature Genet 2000, 25:25-29.

47. Soanes DM, Richards TA, Talbot NJ: Insights from sequencing fungal and oomycete genomes: What can we learn about plant disease and the evolution of pathogenicity? Plant Cell 2007, 19:3318-3326.

48. Kulkarni RD, Kelkar HS, Dean RA: An eight-cysteine-containing CFEM domain unique to a group of fungal membrane proteins. Trends Biochem Sci 2003, 28:118-121.

49. Grell MN, Mouritzen P, Giese H: A Blumeria graminis gene family encoding proteins with a C-terminal variable region with homologues in pathogenic fungi. Gene 2003, 311:181-192.

50. Xue C, Park G, Choi W, Zheng L, Dean RA, Xu JR: Two novel fungal virulence genes specifically expressed in appressoria of the rice blast fungus. Plant Cell 2002, 14:2107-2119.
51. Heath MC: Involvement of reactive oxygen species in the response of resistant (hypersensitive) or susceptible cowpeas to the cowpea rust fungus. New Phytol 1998, 138:251-263.

52. Hu G, Linning R, McCallum B, Banks T, Cloutier S, Butterfield Y, Liu J, Kirkpatrick R, Stott J, Yang G, Smailus D, Jones S, Marra M, Schein J, Bakkeren G: Generation of a wheat leaf rust, Puccinia triticina, EST database from stage-specific cDNA libraries. Mol Plant Pathol 2007, 8:451-467

53. Lamboy JS, Staples RC, Hoch HC: Superoxide dismutase: a differentiation protein expressed in Uromyces germlings during early appressorium development. Exp Mycol 1995, 19:284-296.

54. Rouhier N, Gelhaye E, Gualberto JM, Jordy M-N, De Fay E, Hirasawa M Duplessis S, Lemaire SD, Frey P, Martin F, Manieri W, Knaff DB, Jacquot J-P. Poplar peroxiredoxin Q. A thioredoxin-linked chloroplast antioxidant functional in pathogen defense. Plant Physiol 2004, 134:1027-1038.

55. Rinaldi C, Kohler A, Frey P, Duchaussoy F, Ningre N, Couloux A, Wincker P, Le Thiec D, Fluch S, Martin F, Duplessis S: Transcript profiling of poplar leaves upon infection with compatible and incompatible strains of the foliar rust Melampsora larici-populina. Plant Physiol 2007, 144:347-366.

56. Posada-Buitrago ML, Frederick RD: Expressed sequence tag analysis of the soybean rust pathogen Phakopsora pachyrhizi. Fungal Genet Biol 2005, 42:949-962.

57. El Gueddari NE, Rauchhaus U, Moerschbacher BM, Deising HB: Developmentally regulated conversion of surface-exposed chitin to chitosan in cell walls of plant pathogenic fungi. New Phytol 2002, 156:103-112

58. Link TI, Voegele RT: Secreted proteins of Uromyces fabae: similarities and stage specificity. Mol Plant Pathol 2008, 9:59-66.

59. Mendgen $\mathrm{K}$, Hahn M: Plant infection and the establishment of fungal biotrophy. Trends Plant Sci 2002, 7:352-356.

60. Maier W, Begerow D, Weiß M, Oberwinkler F: Phylogeny of the rust fungi: an approach using nuclear large subunit ribosomal DNA sequences. Can J Bot 2003, 81:12-23.

61. Parkinson J, Blaxter M: SimiTri-visualizing similarity relationships for groups of sequences. Bionformatics 2003, 19:390-395.

62. Martin F, Aerts A, Ahrén D, Brun A, Danchin EGJ, Duchaussoy F, Gibon J, Kohler A, Lindquist E, Pereda V, Salamov A, Shapiro HJ, Wuyts J, Blaudez D, Buée $M$, et al: The genome of Laccaria bicolor provides insights into mycorrhizal symbiosis. Nature 2008, 452:88-92.

63. Stahl EA, Bishop JG: Plant-pathogen arms races at the molecular level. Curr Opin Plant Biol 2000, 3:299-304.

64. Yang Z, Nielsen R, Goldman N, Krabbe Pedersen AM: Codon-substitution models for heterogeneous selection pressure at amino acid sites. Genetics 2000, 155:431-449.

65. Yang Z: PAML: A program package for phylogenetic analysis by maximum likelihood. Comput Appl Biosci 1997, 13:555-556.

66. Nielsen $\mathrm{R}$, Yang Z: Likelihood models for detecting positively selected amino acid sites and applications to the HIV-1 envelope gene. Genetics 1998, 148:929-936.

67. Yang Z: PAML 4: Phylogenetic Analysis by Maximum Likelihood. Mol Biol Evol 2007, 24:1586-1591.

68. Feau N, Joly DL, Hamelin RC: Poplar leaf rusts: model pathogens for a model tree. Can J Bot 2007, 85:1127-1135.

69. Feau N, Bergeron M-J, Joly DL, Roussel F, Hamelin RC: Detection and validation of EST-derived SNPs for poplar leaf rust Melampsora medusae f. sp. deltoidae. Mol Ecol Notes 2007, 7:1222-1228.

70. Tuskan GA, DiFazio S, Jansson S, Bohlmann J, Grigoriev I, Hellsten U, Putnam N, Ralph S, Rombauts S, Salamov A, Schein J, Sterck L, Aerts A, et al: The genome of black cottonwood, Populus trichocarpa (Torr. \& Gray). Science 2006, 313:1596-1604.

71. Miranda M, Ralph SG, Mellway R, White R, Heath MC, Bohlmann J, Constabel CP: The transcriptional response of hybrid poplar (Populus trichocarpa $\times$. deltoides) to infection by Melampsora medusae leaf rust involves induction of flavonoid pathway genes leading to the accumulation of proanthocyanidins. Mol Plant Microbe Interact 2007, 20:816-831.

72. Azaiez A, Boyle B, Levée $V$, Séguin A: Transcriptome profiling in hybrid poplar following interactions with Melampsora rust fungi. Mol Plant Microbe Interact 2009, 22:190-200. 
73. Hahn M, Mendgen $\mathrm{K}$ : Isolation by ConA binding of haustoria from different rust fungi and comparison of their surface qualities. Protoplasma 1992, 170:95-103.

74. Ewing B, Hillier L, Wendl MC, Green P: Base-calling of automated sequencer traces using Phred. I. Accuracy assessment. Genome Res 1998, 8:175-185.

75. The UniProt Consortium: The Universal Protein Resource (UniProt). Nucleic Acids Res 2008, 36:D190-D195.

76. Altschul SF, Madden TL, Schaffer AA, Zhang J, Zhang Z, Miller W, Lipman DJ: Gapped BLAST and PSI-BLAST: A new generation of protein database search programs. Nucleic Acids Res 1997, 25:3389-3402.

77. Eddy SR: Profile hidden Markov models. Bioinformatics 1998, 14:755-763.

78. Emanuelsson O, Nielsen H, Brunak S, von Heijne G: Predicting subcellular localization of proteins based on their $\mathrm{N}$-terminal amino acid sequence. J Mol Biol 2000, 300:1005-1016.

79. Krogh A, Larsson B, von Heijne G, Sonnhammer ELL: Predicting transmembrane protein topology with a hidden Markov model: Application to complete genomes. J Mol Biol 2001, 305:567-580.

80. Klee EW, Ellis LBM: Evaluating eukaryotic secreted protein prediction. BMC Bionformatics 2005, 6:256.

81. Velculescu VE, Zhang L, Vogelstein B, Kinzler KW: Serial analysis of gene expression. Science 1995, 270:484-487.

82. Velculescu VE, Zhang L, Zhou W, Vogelstein J, Basrai MA, Bassett DE Jr, Hieter P, Vogelstein B, Kinzler KW: Characterization of the yeast transcriptome. Cell 1997, 88:243-251.

83. Dinel S, Bolduc C, Belleau P, Boivin A, Yoshioka M, Calvo E, Piedboeuf B, Snyder EE, Labrie F, St-Amand J: Reproducibility, bioinformatic analysis and power of the SAGE method to evaluate changes in transcriptome. Nucleic Acids Res 2005, 33:e26.

84. Thompson JD, Higgins DG, Gibson TJ: CLUSTAL W: improving the sensitivity of progressive multiple sequence alignment through sequence weighting, position-specific gap penalties and weight matrix choice. Nucleic Acids Res 1994, 22:4673-4680

85. Swanson WJ, Nielsen R, Yang Q: Pervasive adaptive evolution in mammalian fertilization proteins. Mol Biol Evol 2003, 20:18-20.

86. Yang Z, Wong WSW, Nielsen R: Bayes empirical Bayes inference of amino acid sites under positive selection. Mol Biol Evol 2005, 22:1107-1118.

doi:10.1186/1471-2164-11-422

Cite this article as: Joly et al:: Comparative analysis of secreted protein evolution using expressed sequence tags from four poplar leaf rusts (Melampsora spp.). BMC Genomics 2010 11:422.

\section{Submit your next manuscript to BioMed Central and take full advantage of:}

- Convenient online submission

- Thorough peer review

- No space constraints or color figure charges

- Immediate publication on acceptance

- Inclusion in PubMed, CAS, Scopus and Google Scholar

- Research which is freely available for redistribution

Submit your manuscript at www.biomedcentral.com/submit
C Biomed Central 